\title{
Assessing and Mapping Climate Change Vulnerability with the Help of GIS: Example of Burundi
}

\author{
Daniel BECKER, Kathrin RENNER and Stefan SCHNEIDERBAUER \\ EURAC Research, Bolzano / Italy·daniel.becker@eurac.edu
}

This contribution was double-blind reviewed as extended abstract.

\begin{abstract}
Vulnerability assessments are important instruments to reveal the most harmful impacts of climate change on the environment and society. They are applied by development agencies to identify hotspot regions of climate change and to formulate appropriate adaptation measures. In this context, our work contributes to standardise the approach of vulnerability assessments, and to stress the need of geographic information systems as key instruments in order to include spatial analysis and vulnerability mapping in the assessment and visualisation of outputs. Preliminary results from a vulnerability assessment carried out for Burundi show the possibilities of such an approach, but also illustrate the constraints, which lie mainly in the evaluation of impacts and the reliability and heterogeneity of datasets.
\end{abstract}

\section{Introduction}

Adaptation to climate change impacts has become one of the central concerns of the international development cooperation. In order to identify the populations, regions, or sectors most susceptible to climate change effects, international and national decisionmakers, planners, and development agencies increasingly draw on the results of vulnerability assessments (SCHIPPER \& BURTON 2009). However, given the multitude of definitions of vulnerability and related terms, as well as the variety of methodologies, a clear conceptual approach for operationalizing and visualising vulnerability is so far missing (GALLOPIN 2006). Against this background, we propose a standardised indicatorbased approach to assess climate change vulnerability in developing countries. GIS in this context is an essential tool, which is utilized from the very beginning of the assessment, including data management, spatial analysis, communication, mapping and monitoring of results (KIENBERGER et al. 2009). It allows the detection of differences in vulnerability in space, and, depending on data availability, to study the phenomenon at different spatial scales.

We elaborated and tested our approach in the context of GIZ-financed development projects and first applied the method in a project on climate change adaptation in Burundi. The assessment's aim was to identify those Burundian regions, which are the most 
vulnerable to potential impacts of climate change. The focus lied on water and soil resources, as soil erosion and drought are considered the most harmful impacts in Burundi.

\section{Our Approach to Assess and Map Vulnerability}

The approach is based on a pragmatic interpretation and implementation of the IPCC AR4 concept. According to the IPCC, vulnerability is the degree to which a system is susceptible to or unable to cope with the adverse effects of climate change. In this definition, vulnerability is a function of three components: the exposure of a system and dependent on the character, magnitude and rate of climate variation, the system's sensitivity, and its adaptive capacity, which includes potential additional adaptation activities (IPCC 2007):

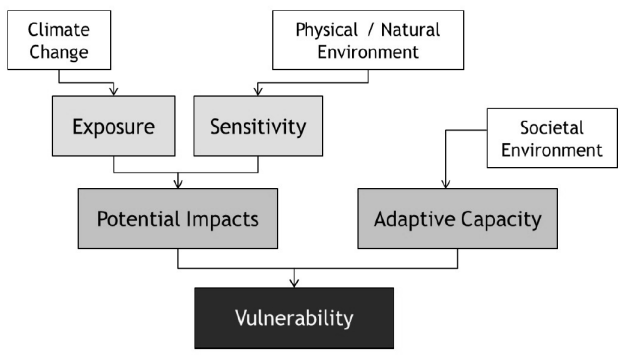

Fig. 1:

The components constituting vulnerability according to the IPCC concept

The three vulnerability components are composed of so-called factors, which again are composed of different indicators describing each factor. Indicators in this term must be available spatially referenced, so that they can be utilised in GIS for aggregating the components to the potential impact and vulnerability. Following this approach, we identified six key steps of vulnerability assessment and mapping:

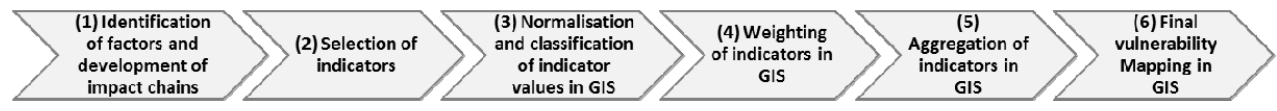

Fig. 2: The six steps of vulnerability assessment and mapping

(1) Impact chains provide the means to understand the cause-effect relationships that lead to climate change vulnerability (DUBOIS et al. 2011). Starting from an identified key potential impact (e.g. soil erosion), the aim is to identify contributing factors for the three vulnerability components. (2) The selected indicators subsequently enable the calculation of exposure, sensitivity and adaptive capacity through aggregation. The selection of suitable indicators is a key element in this part of the methodology since they compose the final vulnerability map. (3) Before aggregating the indicators, we transform the values in GIS into a standardised reference unit and value range (normalisation). The classification is necessary in order to evaluate the indicator values in terms of their contribution to the potential impact (e.g. \% of slope for soil erosion). (4) Applying a weighting to indicators is done in those cases where some of the indicators are considered to have a larger influence on a vulnerability component than others (they thus receive a larger weight during the aggregation process). (5) Once the different indicators have been classified and weighted, we aggregate them in GIS to exposure, sensitivity and adaptive capacity, which later form 
the (6) final vulnerability map. GIS in this last stage provides a multitude of tools for the visualisation of the vulnerability outputs.

\section{$3 \quad$ Preliminary Results from Burundi}

Together with local experts and stakeholders, we identified soil erosion and drought as the most important potential impacts of climate change in Burundi. The following selection of contributing factors and indicators is directly linked to the availability of reliable data. We used a variety of data sets from national and global sources (regional climate models, LULC layers, population density statistics, digital elevation models, etc.). Table 1 shows the identified factors, indicators and data sources for the potential impact soil erosion and exemplary for the sensitivity component:

Tab. 1: Factors, indicators and data sources of sensitivity for soil erosion

\begin{tabular}{|l|l|l|}
\hline Sensitivity Factors & Indicator & Data Source \\
\hline Land use land cover & LULC class & AfriCover (FAO) \\
\hline Soil type & Soil class & SOTERCAF (FAO) \\
\hline Population Density & Number of inhabitants per km ${ }^{2}$ & $\begin{array}{l}\text { Census data (Ministry } \\
\text { of Statistics of Burundi) }\end{array}$ \\
\hline Slope type & Slope in \% and slope length in $\mathrm{m}$ & $\begin{array}{l}\text { 10m DEM (Geoinformation } \\
\text { Institute of Burundi) }\end{array}$ \\
\hline Anti-erosion measures & $\begin{array}{l}\text { \% of agricultural parcels with at } \\
\text { least one anti-erosion measure } \\
\text { (per province) }\end{array}$ & $\begin{array}{l}\text { Agricultural survey (Ministry } \\
\text { of Agriculture of Burundi) }\end{array}$ \\
\hline Crop type & $\begin{array}{l}\text { Total cultivated surface of crop } \\
\text { types in ha (per province) }\end{array}$ & $\begin{array}{l}\text { Agricultural survey (Ministry } \\
\text { of Agriculture of Burundi) }\end{array}$ \\
\hline
\end{tabular}

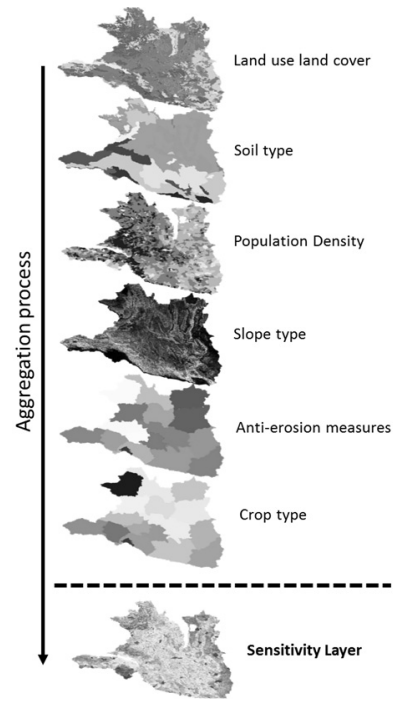

Fig. 3:

Aggregation of sensitivity for soil erosion
We normalized and classified the indicator values together with local experts in a stakeholder workshop in Burundi. The slope types, for example, were evaluated differently according to their susceptibility to soil erosion.

Then we converted the values into raster layers, which at this point were very helpful to illustrate the regional differences and encourage the discussion regarding the weighting of indicators. Concerning the sensitivity component, the stakeholders evaluated slope type and population density indicators as very important for soil erosion processes in Burundi.

In order to calculate the exposure, sensitivity and adaptive capacity layer, we aggregated the pixel values with the weighted arithmetic aggregation method in GIS (figure 3 illustrates the aggregation process for the sensitivity component). The final vulnerability map is then produced by

adding the exposure layer to the sensitivity layer (= potential impact layer) and subtracting the adaptive capacity layer from the potential impact layer (= vulnerability layer). The most 
vulnerable regions are visible through the aggregated indicator values and their regional disparities.

\section{$4 \quad$ Possibilities and Constraints}

Our indicator-based approach of assessing and mapping vulnerability is strongly dependent on the application in a GIS, which goes beyond a simple mapping of vulnerability. Evaluating spatial data adequately within a vulnerability assessment requires integrating local knowledge and expertise for the evaluation and weighting of the various input indicators. Particularly in developing countries, this type of knowledge is often acquired by means of workshops with stakeholders and local experts. Potentially, GIS can serve as participatory instrument for discussing different vulnerability factors or suitable indicators, or as a platform of visualisation and monitoring of vulnerability results (e.g. through a webGIS).

Since vulnerability assessments are highly complex and cover a broad field of scientific research, a wide range of data on different spatial and temporal scales, is needed. In this context, the constraints of our approach lie particularly in the strong dependency of reliable datasets and suitable indicators. Also, the heterogeneity of spatial scales and resolutions of datasets is not clearly solved. It is often challenging to combine as much information as possible in the maps in order to provide transparent and verifiable results.

Nevertheless, this standardised approach of vulnerability assessments and mapping cannot only illustrate climate change vulnerability, but also provide scientific input to the development of adaptation measures by development agencies on a regional and national level. Furthermore, the assessments can be suitable to assist the monitoring and evaluation of adaptation efforts in future.

\section{References}

Dubois, N., Caldas, A., Boshoven, J. \& Delach, A. (2011), Integrating Climate Change Vulnerability Assessments into Adaptation Planning: A Case Study Using the NatureServe Climate Change Vulnerability Index to Inform Conservation Planning for Species in Florida, Washington D.C.

GALLOPIN, G. C. (2006), Linkages between vulnerability, resilience, and adaptive capacity; Global Environmental Change, 16 (3), 293-303.

IPCC (2007), Climate Change 2007: Impacts, Adaptation and Vulnerability. Contribution of Working Group II to the Fourth Assessment Report of the Intergovernmental Penal on Climate Change. Ed. by PARRY, M. L. et al. (Eds.), Cambridge University Press, Cambridge, UK, 976 p.

KienBerger, S., LANG, S. \& ZeIL, P. (2009), Spatial vulnerability units - expert-based spatial modelling of socioeconomic vulnerability in the Salzach catchment, Austria. In: Natural Hazards Earth System Sciences, 9, 767-778.

SCHIPPER, E. L. F. \& BURTON, I. (2009), Understanding adaptation: origins, concepts, practice and policy. In: SCHIPPER, E \& BURTON I. (Eds.), The earthscan reader on adaptation to climate change. London, UK and Sterling, VA, USA, 1-9. 